\title{
NHS staff should inform patients of negligent acts
}

Clare Dyer legal correspondent, BMJ

Doctors and managers in the NHS will be placed under a statutory "duty of candour" requiring them to tell patients when a negligent act or omission causes harm, under plans for sweeping reform of the clinical negligence system unveiled this week.

A new NHS "redress scheme" will offer a compensation package of remedial care, apologies, and compensation up to $£ 30000$ (\$49670; €43 170) without the need for litigation, and no-fault compensation for babies with severe birth related neurological damage. The redress scheme, to be administered by a new body based on the NHS Litigation Authority, is the key plank of Making Amends, the long awaited report from the chief medical officer, Professor Liam Donaldson. The consultation paper makes 19 recommendations but rejects the full no-fault compensation scheme that many doctors wanted. Doctors at the BMA's annual representative meeting in Torquay this week overwhelmingly passed a motion supporting a full system of no fault compensation for clinical errors, with maximum financial limits.

Patients covered by the proposed new redress scheme will have the option of litigation instead if they choose, but they will waive their right to litigate if they accept compensation under the scheme. The redress scheme will be closely aligned to the new NHS complaints procedure, and making a claim for compensation will no longer be a disqualification for pursuing a complaint. Compensation under the scheme, which would initially cover the hospital sector but could be extended to primary care, will be paid for "serious shortcomings in NHS care if the harm could have been avoided."

Statutory provisions aimed at ending the "culture of blame" would give protection from disciplinary action to doctors and others who report medical errors, except for criminal offences and cases where it would not be safe for the professional to continue to treat patients. Brain damaged babies currently account for $5 \%$ of compensation claims but $60 \%$ of the clinical negligence budget. Under the proposals, parents would be provided with a managed medical care package for their child, monthly payments for other care of up to $£ 100000$ a year, lump sum payments for home adaptations and equip-

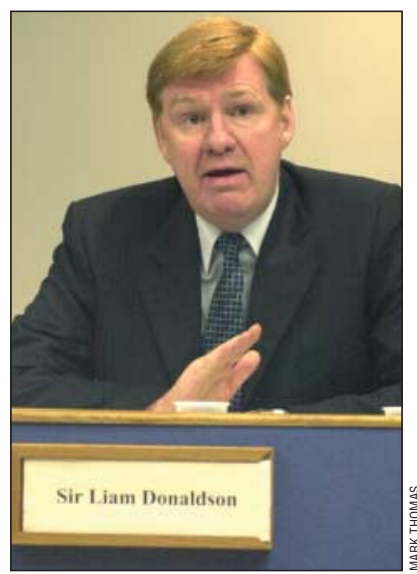

Professor Liam Donaldson's report calls for candour ment of up to $£ 50000$, and compensation for pain and suffering, capped at $£ 50000$.

The Medical Protection Society and the Medical Defence Union welcomed the report, particularly the no-fault scheme for neurologically impaired babies.

Groups representing patients and lawyers were more cautious. Peter Walsh, chief executive of Action for Victims of Medical Accidents, said there was a risk that without independent advice "people will feel under pressure to settle for what could be much less than they need or deserve."

David Marshall, president of the Association of Personal Injury Lawyers, said: "It is vital that patients are given the freedom to consider any offer with an independent lawyer who can help to ensure the patient receives the package which is most suitable."

Making Amends is available on the Department of Health's website at www.doh.gov.uk/makingamends

\section{Drug helps patients with relapsed myeloma}

Janice Hopkins Tanne New York

Bortezomib, the first of a new class of drugs called proteasome inhibitors, produced a $35 \%$ response rate in patients with relapsed, refractory multiple myeloma, an unusually high rate in these patients, for whom there is no other treatment.

A phase II study published in the New England Journal of Medicine (2003;348:2609-17) led the US Food and Drug Administration to grant accelerated approval to Millennium Pharmaceuticals to provide the drug to patients whose disease had relapsed after two treatments and was resistant to the last treatment. The drug was previously known as PS-341 and is marketed as Velcade.

"It is a new approach. The drug targets tumour cells and the bone marrow microenvironment" [making it less hospitable to tumour growth], said Dr Kenneth Anderson, director of the Jerome Lipper Multiple Myeloma Center at the Dana-Farber Cancer Institute in Boston.

"Proteasomes are present in normal and cancerous cells.
They degrade proteins as part of normal protein turnover. Proteasome inhibitors modulate the pattern of protein breakdown, resulting in tumour cell death or inhibition of tumour cell growth, survival, and drug resistance," he said.

The trial involved 202 patients with relapsed myeloma that was resistant to the most recent treatment they had received. Of these patients 193 could be evaluated. Patients were treated with a dosage of $1.3 \mathrm{mg}$ of bortezomib per square metre of body surface area, given twice a week intravenously for two weeks, followed by one week without treatment, for up to eight cycles. Patients who had suboptimal responses also received $20 \mathrm{mg}$ of dexamethasone orally on the day of treatment and the day after

Sixty seven $(35 \%)$ of the 193 patients who could be evaluated had a complete, partial, or minimal response to bortezomib alone. Nineteen had a complete or near complete response, and for 12 of them the response was the best they had had to any treatment.

"There are three messages: the extent and frequency of the response, the durability of the response-12 months-and the survival of 16 months, when six months was predicted.

"The challenges are to study the effect of the drug earlier in the disease and to combine it with conventional treatments [such as chemotherapy and radiation] and with newer agents," Dr Anderson said. 